\title{
Eight-step method to build the clinical content of an evidence-based care pathway: the case for COPD exacerbation
}

\author{
Cathy Lodewijckx ${ }^{1,2,3^{*}}$, Marc Decramer ${ }^{1,4}$, Walter Sermeus ${ }^{2,3}$, Massimiliano Panella ${ }^{5,3}$, Svin Deneckere ${ }^{2,3}$
} and Kris Vanhaecht ${ }^{2,3,6}$

\begin{abstract}
Background: Optimization of the clinical care process by integration of evidence-based knowledge is one of the active components in care pathways. When studying the impact of a care pathway by using a cluster-randomized design, standardization of the care pathway intervention is crucial. This methodology paper describes the development of the clinical content of an evidence-based care pathway for in-hospital management of chronic obstructive pulmonary disease (COPD) exacerbation in the context of a cluster-randomized controlled trial (CRCT) on care pathway effectiveness.

Methods: The clinical content of a care pathway for COPD exacerbation was developed based on recognized process design and guideline development methods. Subsequently, based on the COPD case study, a generalized eight-step method was designed to support the development of the clinical content of an evidence-based care pathway.

Results: A set of 38 evidence-based key interventions and a set of 24 process and 15 outcome indicators were developed in eight different steps. Nine Belgian multidisciplinary teams piloted both the set of key interventions and indicators. The key intervention set was judged by the teams as being valid and clinically applicable. In addition, the pilot study showed that the indicators were feasible for the involved clinicians and patients.

Conclusions: The set of 38 key interventions and the set of process and outcome indicators were found to be appropriate for the development and standardization of the clinical content of the COPD care pathway in the context of a CRCT on pathway effectiveness. The developed eight-step method may facilitate multidisciplinary teams caring for other patient populations in designing the clinical content of their future care pathways.
\end{abstract}

Keywords: Critical pathway, Evidence based medicine, Standardization, Cluster randomized trial, Chronic obstructive pulmonary disease

\section{Background}

Standardization of the clinical care process through integration of evidence-based knowledge has proven to be an effective strategy for reducing unwanted variations in treatment and for minimizing the probability of medical errors [1]. However, major difficulties arise when introducing evidence and clinical guidelines into routine daily

\footnotetext{
* Correspondence: cathy.lodewijckx@med.kuleuven.be

'Respiratory Department, University Hospitals Leuven, Leuven, Belgium ${ }^{2}$ Department of Public Health, KU Leuven University of Leuven, Leuven, Belgium

Full list of author information is available at the end of the article
}

practice, and many patients, as a result, do not receive appropriate care, or receive unnecessary or harmful care [2-5].

A possible tool to facilitate implementation of evidence into practice is a care pathway. Care pathways are complex interventions for mutual decision making, organization, and standardization of predicTable care for a well-defined group of patients during a well-defined period [6-8]. One of the active ingredients in care pathways is the integration of a set of evidence-based key interventions $[8,9]$.

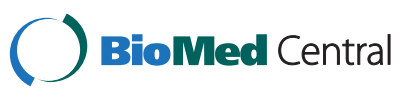


Care pathways induce change at different levels of the organization (that is, patient, team, hospital); consequently, variability at individual level outcomes may reflect the impact of higher-level complexity processes. To deal with these multilevel effects, cluster randomized designs are strongly recommended when studying the impact of care pathways [10,11]. Importantly, in cluster randomized controlled trials (cRCTs) the care pathway under evaluation is implemented at different sites. Consequently, a challenge within cRCT designs is to standardize the intervention in order to deliver the 'same' intervention at the different sites under study [10,12-14]. Standardization in complex interventions refers to adaptation of the care pathway components to the context level, without compromising the integrity of the intervention being evaluated across multiple sites $[10,14,15]$.

In 2009, the European Pathway Association (E-P-A) launched the European Quality of Care Pathways (EQCP) study, an international cRCT addressing the impact of a care pathway for chronic obstructive pulmonary disease (COPD) exacerbations [9]. In the context of the EQCP study, the clinical content of a model COPD care pathway - implementable at the different experimental sites - needed to be developed, including a set of clinically applicable evidence-based key interventions and a set of reliable process and outcome indicators. This paper describes the development of the clinical content of a care pathway for in-hospital management of COPD exacerbation.

\section{Methods}

The clinical content of an evidence-based care pathway for COPD exacerbation was developed based on the process design methodology developed by Berry et al. [16], and the guideline development methods of the American College of Chest Physicians (ACCP) [17], the World Health Organization (WHO) [18] and the Healthcare Infection Control Practices Advisory Committee (HICPAC) [19]. Subsequently, based on the experiences of the COPD case, a generalized eight-step method for development of the clinical content of an evidence based care pathway was designed (Figure 1). This study was approved by the ethical committee of the University Hospitals Leuven as previously published in this journal [9].

\section{Results}

A set of 38 evidence-based key interventions and a set of 24 process and 15 outcome indicators were developed in eight different steps. Both sets are displayed in Additional file 1 and Additional file 2, respectively. In the following section, description and rationale for each development step is presented.

\section{Step 1: Selection of the care population and selection of an expert panel}

The patient population under study was specified as 'Patients hospitalized with COPD exacerbation'. To ensure clinical validity and feasibility of the end product, an expert panel was involved in each step of the development method. This panel was composed of the following: (i) three clinicians with internationally recognized clinical and scientific expertise in COPD exacerbations: a respiratory physician (MD) who is also president of the European Respiratory Society, a physiotherapist (TT) who specializes in pulmonary rehabilitation, and a clinical nurse specialist in COPD (CL); (ii) an epidemiologist (MP) who specializes in organization of primary and secondary chronic care; and (iii) two professors (WS, KV) in patient care management who have extensive clinical and scientific expertise in development and implementation of care pathways $[8,18-21]$. All six experts had extensive research experience.

\section{Step 2: Literature review and extraction of clinical activities}

To identify all available evidence for integration in the evidence-based COPD care pathway, an extensive literature review was conducted by the main researchers, CL and KV (Figure 2). First, an initial literature search was carried out in April 2008 in the context of the Delphi study, and an updated search was performed in June 2011. In the following section, the updated search is described [22].

The following resources were explored: (I) websites of international respiratory societies: American Thoracic Society (ATS) (www.thoracic.org); British Thoracic Society (BTS) (www.brit-thoracic.org.uk); European Respiratory Society (ERS) (www.ersnet.org); Global Strategy for Diagnosis, Management, and Prevention of COPD (GOLD) (www.goldcopd.org); National Institute for Health and Clinical Excellence (NICE) (www.nice.org.uk); Scottish Intercollegiate Guidelines Network (SIGN) (www.sign.ac. uk); (II) Public resources for evidence-based clinical practice guidelines (www. guideline.gov, www.g-i-n.net); (III) electronic databases including Medline and Embase and Cochrane; (IV) available process flow diagrams founded on evidence-based medicine (www.mapofmedicine.com, http://group.bmj.com/products/evidence-centre.com).

For guidelines developed by international societies, only those guidelines were considered that were updated within the last five years. For PubMed and Cochrane, we used the MeSH terms 'COPD' combined with (i) 'practice guideline', (ii) 'disease exacerbation and patient care management', and (iii) 'outcomes'. For Embase, we used the $\mathrm{MeSH}$ terms 'chronic obstructive lung disease' combined with (i) 'practice guideline' and (ii) 'disease exacerbation and patient care', and (iii) 'outcomes'. Non-MeSH 


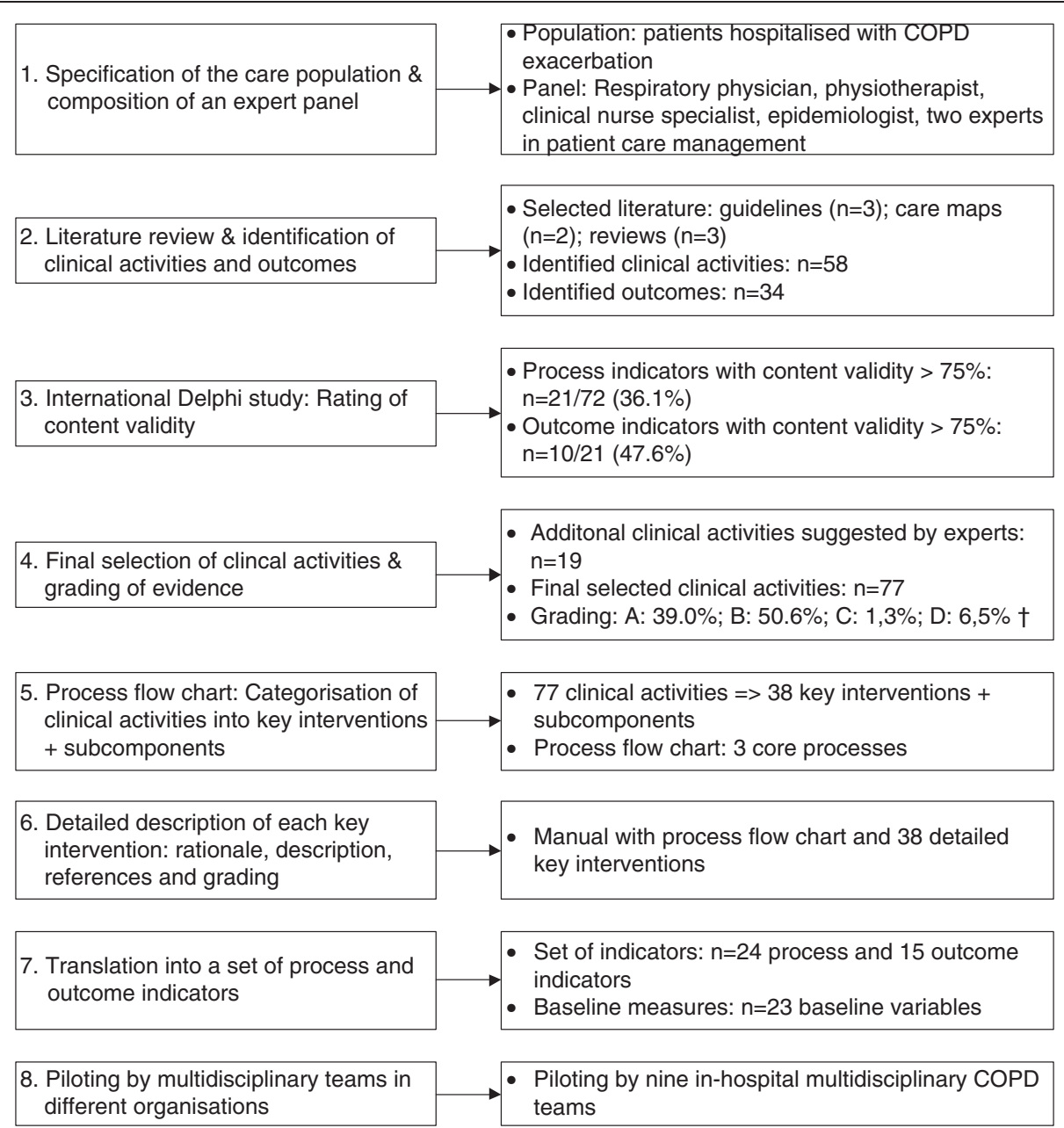

Figure 1 Eight-step method for development of the clinical content of an evidence based care pathway: the case for COPD exacerbation.

terms used in Embase were 'COPD' in combination with 'exacerbation and management'. Search limit parameters included: (i) published between 2005 and 2011, and (ii) written in English, French, German, Italian or Dutch.

Second, we performed a two-phase screening evaluation of publications selected from websites of the respiratory societies, Map of Medicine and the electronic databases. In the first phase, publications were appraised for relevance based on appropriateness of the title and abstract. If relevance was unclear, or if the abstract was unavailable, the publication was included for further appraisal of the full text. In the second phase, two independent researchers ( $\mathrm{CL}$ and $\mathrm{KV}$ ) reviewed the full text of the selected guidelines, reviews or process flow diagrams. The following inclusion criteria were used: (i) reportage of clinical processes and outcomes regarding in-hospital management of COPD exacerbation; (ii) evidence was reported in terms of guidelines, process flow diagrams, reviews or overview papers; (iv) published between 2005 and 2011; (v) published in English, French, German, Italian or Dutch; and (vi) quality of underlying evidence can be appraised by in-text references. The literature research revealed initially three guidelines, one process flow diagram, and 2,939 digital records from the electronic medical databases (Figure 2). After exclusion of irrelevant publications ( $\mathrm{n}=$ 2,851 ), and after appraisal of full text, three guidelines, two process flow diagrams, and 37 reviews were included for development of the evidence-based clinical content of the COPD care pathway [5,23-56].

Finally, the selected literature was thoroughly screened for identification of all possible clinical activities and outcomes related to in-hospital management of COPD exacerbation. The detected clinical activities were extracted and listed, and the corresponding literature sources were recorded. In total, 58 different clinical activities were extracted from the selected literature (Table 1, no. 1-58). Besides these, 34 outcome categories were identified (Table 2). 


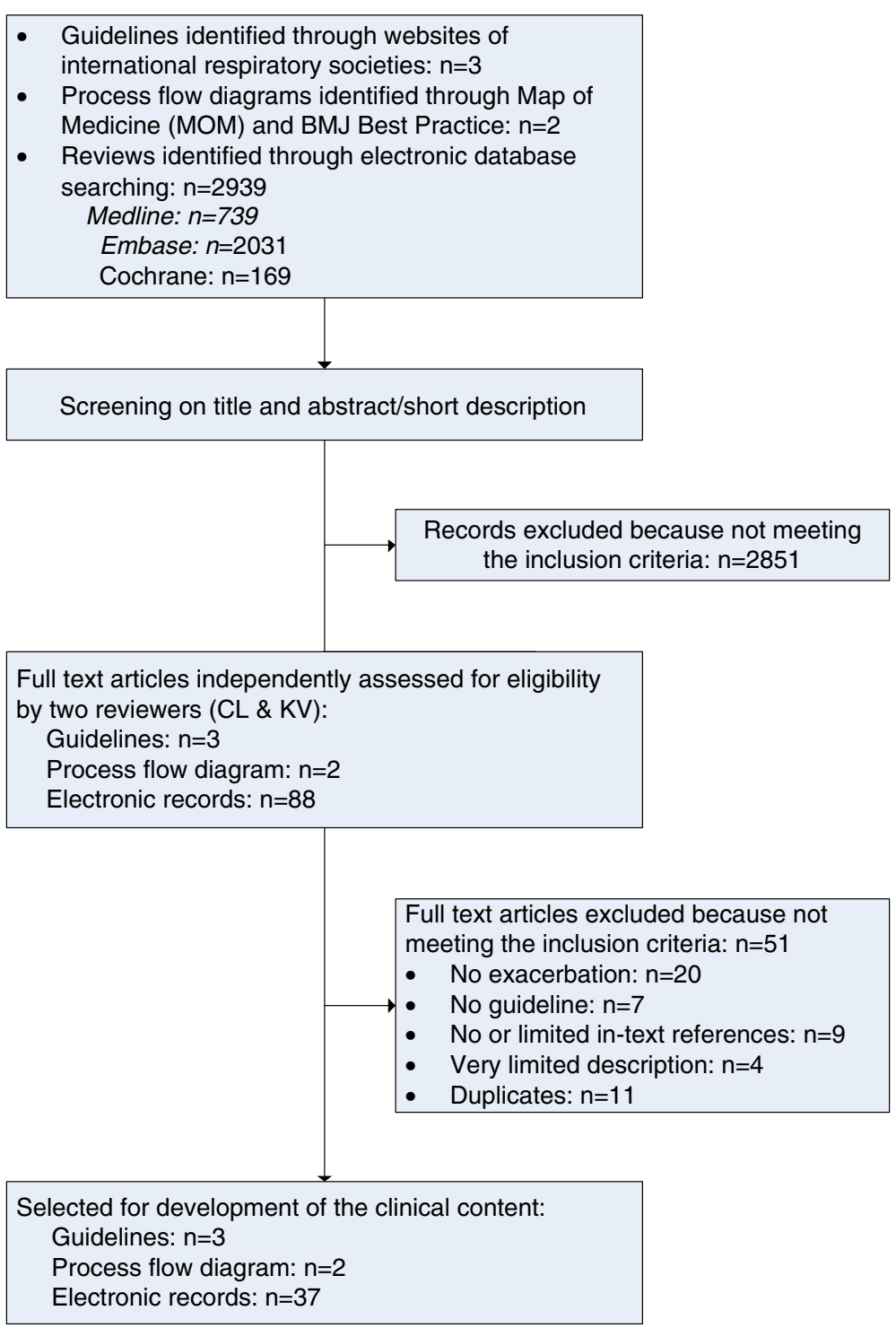

Figure 2 Literature search strategy.

\section{Step 3: International Delphi study for rating of content} validity

Content validity was rated for 72 process and 21 outcome indicators by conducting an international Delphi study with a panel composed of 35 medical professionals from 15 countries. This panel consisted of 19 medical doctors, 8 nurses and 8 physiotherapists. The detailed methodology and the results of this study were published elsewhere [57-60].

In summary, panelists were asked to rate the relevance for follow-up of the process and outcome indicators in care pathways for COPD exacerbations. Consensus was defined as agreement by at least $75 \%$ of the panel members that an indicator is relevant for follow-up. Consensus was reached for 26 of 72 process indicators (36.1\%) and
10 of 21 outcome indicators (47.6\%). Highest consensus was reached for the process indicators for oxygen therapy (100\%), pulmonary rehabilitation (100\%), and patient education ( 94.5 to $88.6 \%$ ), and for the outcome indicators for understanding of therapy (91.4 to $85.7 \%)$ and selfmanagement (88.6 to $88.2 \%$ ) [60].

\section{Step 4: Final selection of the clinical activities and grading of evidence}

First, the list of 58 extracted clinical activities (step 2), together with the Delphi results (step 3), were sent to the clinical experts of the panel (MD, TT and CL) with a request to complete two tasks: (i) to review the 58 identified activities for validity and feasibility; and (ii) if indicated, to propose any additional clinical activity they 


\section{Table 1 Clinical activities for management of patients hospitalized with COPD exacerbation}

1. Medical history before exacerbation: prior measures of lung function $(B)^{*}$

2. Medical history before exacerbation: spirometric classification of severity (B)

3. Medical history before exacerbation: documenting frequency and

severity of attacks of breathlessness (B)

4. Medical history before exacerbation: documenting frequency and severity of chronic cough (B)

5. Medical history before exacerbation: history of chronic

sputum production (B)

6. Medical history before exacerbation: documenting possible limitation of daily activities (B)

7. Medical history before exacerbation: prior arterial blood gas

measurements in sTable condition (B)

8. Medical history before exacerbation: number of previous exacerbations in the previous year (B)

9. Medical history before exacerbation: number of previous hospitalizations (B)

10. Medical history before exacerbation: pre-existing co-morbidities (A)

11. Medical history before exacerbation: present treatment regimen (A)

12. Medical history before exacerbation: smoking status (B)

13. Medical history before exacerbation: sleeping and eating difficulties (B)

14. Assessment of symptoms: physical examination (B)

15. Assessment of differential diagnosis (B)

16. Assessment of co-morbidities (B)

17. Temperature $(B)$

18. Pulse rate (B)

19. Blood pressure (B)

20. Alertness (B)

21. Skin color (B)

22. Pulse oximetry (D)

23. Arterial blood gas measurement: At admission (B)

24. Arterial blood gas measurement: prior to discharge in

patients hypoxemic during a COPD exacerbation (B)

25. Arterial blood gas measurement: in the following three

months in patients hypoxemic during a COPD exacerbation (D)

26. Arterial blood gas measurement: after discharge in patients

with long term oxygen therapy (LTOT) (B)

27. Chest $X$-ray (B)

28. ECG (B)

29. Blood examination: hematology (B)

30. Blood examination: biochemical tests (B)

31. Blood examination: theophylline level in patients on theophylline therapy at admission (B)

32. Sputum culture and anti-biogram (B)

33. Spirometry during hospitalization (not earlier than Day 3 because of acute condition) (C)

34. Admission to ICU if exacerbation is life threatening (B)

35. Controlled oxygen therapy in hypoxemic patients (A)

36. Assisted ventilation if necessary (A)
37. Smoking cessation advice when active smoker (A)

38. Appropriate prescription of short-acting bronchodilatators (A)

39. Appropriate prescription of long-acting bronchodilatators

( $\beta$-agonists and/or anticholinergics) (A)

40. Appropriate prescription of inhaled corticosteroids (A)

41. Appropriate prescription of glucocorticosteroids: oral or intravenous (A)

42. Appropriate prescription of methylxanthines (theophylline or aminophylline) (A)

43. Antibiotics in patients if indicated (A)

44. Patient education information about recognition and treatment of exacerbation (A)

45. Patient education: instruction on how to use inhalers (A)

46. Chest physiotherapy: sputum clearance (A)

47. Referral to pulmonary rehabilitation (A)

48. Monitoring of fluid balance (A)

49. Fluid administration in dehydrated patients (A)

50. Supplementary nutrition in patients with $\mathrm{BMI}<20$ (B)

51. Screening and update of vaccination status (B)

52. Deep venous thrombosis prophylaxis (A)

53. Treatment of co-morbid conditions (A)

54. Initiation of long-term oxygen therapy (LTOT) if the

patient remains hypoxemic (A)

55. Assessment of medical discharge criteria (D)

56. Assessment and management of home situation (A)

57. Oral information and discharge letter regarding prescribed home therapy and follow-up appointment (B)

58. Arrangement of follow-up appointment four to six weeks after discharge (D)

59. Medical history before exacerbation: number of previous admissions to ICU (D)

60. Medical history before exacerbation: cardiovascular status (B)

61. Glucose monitoring (B)

62. CT THORAX: $1 \mathrm{X}$ year (B)

63. ECHO CARDIO: $1 \mathrm{X}$ year (B)

64. Patient education: information about the nature of COPD (A)

65. Patient education: self-management plan (A)

66. Patient education strategies for minimizing dyspnoea (A)

67. Patient education information about oxygen treatment (A)

68. Physiotherapy: breathing techniques (A)

69. Physiotherapy: Activities of Daily Life (A)

70. Physiotherapy: positioning (A)

71. Identification for pulmonary rehabilitation determinant (B)

72. Body mass index (BMI) determinant (A)

73. Screening for weight loss (A)

74. Referral to dietician in patient with obesity or cachexie (B)

75. Assessment and management of anxiety and depression (B)

76. Information letter for general practitioner (B)

77. Discharge checklist (B) believe is essential for in-hospital management of COPD exacerbations and which is lacking in the current activity list of clinical activities. Second, a consensus meeting was held with the entire expert panel in order to make a final selection of the clinical activities. As a result, all 58 clinical activities were appraised to be valid and feasible. In addition, 19 clinical activities beyond the 58 original ones were included (Table 1, nos. 59-77). Interestingly, for almost all these additional clinical activities, a more or less comprehensive description was available in the guidelines for management of stable COPD $[27,32,61]$.

Finally, the strength of the evidence for the final 77 clinical activities was graded, so that clinicians know how much confidence they can place on the clinical recommendations included in the clinical care pathway [62]. The grading was performed by the clinical nurse specialist (CL) using the SIGN approach [63]. The grading approach of SIGN was chosen because this grading 
- Readmission: 30-day, 3-month, 6-month, 1-year

- Number of hospital admissions

- Interval before next admission

- Frequency and severity of exacerbation

- Mortality: in-hospital, 30-day, 3-month, 6-month, 1-year

- Survival: 1-year

- Length of stay (LOS)

- Level of understanding of inhaler therapy

- Compliance with home oxygen therapy

- Performance of physical exercise

- Smoking status: 30-day, 3-month, 6-month, 1-year

- Symptoms of anxiety and depression

- Health-related quality of life (HRQL): symptoms, disability, morbidity and quality of life; psychological well-being) - Health status

- Quality-adjusted life expectancy measure (QALY) and

disability adjusted life years (DALY)

- Functional capacity

- Exercise capacity

- Physical performance: 6-minute walking distance (6-MWD), 20-MWD, shuttle walk test, maximum workload, treadmill time, maximum oxygen uptake, quadriceps strength, hand grip force, maximal inspiratory mouth pressure

- Severity of breathlessness: dyspnea, symptoms at rest and during exercise
- Inhaled $\beta$-agonist therapy is required no more frequently

than every four hours

- Patient, if previously ambulatory, is able to cope with basic needs

in his/her situation, in usual environment

- Patient is able to eat and sleep without frequent awakening by dyspnoea

- Patient has been clinically sTable for 12 to 24 hours

- Last measure of arterial blood gases (ABGs) were accepTable

according to condition of the patient

- Patient and/or home caregiver fully understands correct use of therapy:

oral medication therapy, inhaler therapy, oxygen therapy if home

oxygen therapy

Patient, family, and physician are confident that the patient can

manage successfully

- Lung function parameters: forced expiratory volume in one

second $\left(\mathrm{FEV}_{1}\right)$, forced vital capacity (FVC), inspiratory capacity

- Quality of sleep

- Nutritional status

- Patients' perception of coordination between hospital and

home healthcare

- Patient satisfaction with therapy and care

- Adverse event related to regular clinical examination by an investigator

- Cost of illness (COI) analysis

- Absenteeism system is very transparent and provides a simplistic grading of evidence [62-64]. Importantly, if the level of evidence could not be derived based on the literature selected in step 2, an additional literature search was performed in Medline, Embase and Cochrane. Search terms included 'COPD' and key words related to the particular key intervention. Primarily, the search for additional evidence was focused on reviews performed according to standard criteria for reviews [22]. If not available, an additional search for clinical trials was conducted. Subsequently, two other clinical experts of the panel (MD and TT) checked the final grading. As a result, 30 activities were graded as evidence for level A (39.0\%), 41 activities as level B (53.2\%), 1 activity as level $\mathrm{C}(1.3 \%)$, and 5 as level D (6.5\%) (Table 1$)$.

An extensive list of care activities was generated by following the above-mentioned steps. However, providing such an exhaustive list of 77 care activities to the multidisciplinary teams would likely not encourage them to use this evidence in practice. Therefore, the next two steps were specifically undertaken to distil the list of care activities to a set of key interventions that would be useable and manageable in clinical practice.

\section{Step 5: Clustering of clinical activities into key interventions and categorization into process flow diagram}

First, the 77 clinical activities were clustered into key interventions with subcomponents, based on the following criteria: (i) clinical activities are inextricably linked to each other (that is, measurement of basal metabolic index, advice on malnutrition, supplementary nutrition and so on were clustered into 'nutrition'); (ii) clinical activities need to be performed by a specific team member (that is, breathing exercises, positioning and so on were categorized under physiotherapy); (iii) clinical activities need to be performed at a specific time point or within a specific time span of the care process (that is, activities regarding discharge management). As a result, the 77 clinical activities were clustered into 38 key interventions, with 9 of them comprising 2 to 15 subcomponents.

Second, the key interventions were categorized into three core processes (diagnostic, pharmacological and non-pharmacological management), and subsequently presented by means of a process flow diagram. In addition, within each of three core processes, key interventions were grouped into care blocks based on the overall content of these key interventions (for example, education, ventilation). The process flow diagram with the 38 key interventions is displayed in Additional file 1.

\section{Step 6: Detailed description of the key interventions}

For each key intervention, the following components were included in the detailed description: (i) rationale, which addresses why it is of crucial importance that the key intervention is performed, and which describes expected impact on patient outcomes; (ii) description, which defines the exact content of the key intervention; (iii) in-text references and reference list; and (iv) grading of evidence. An example of a detailed description of a key intervention on arterial blood gas measurements is provided in Figure 3. In order to search for detailed 


\section{Arterial blood gas measurement}

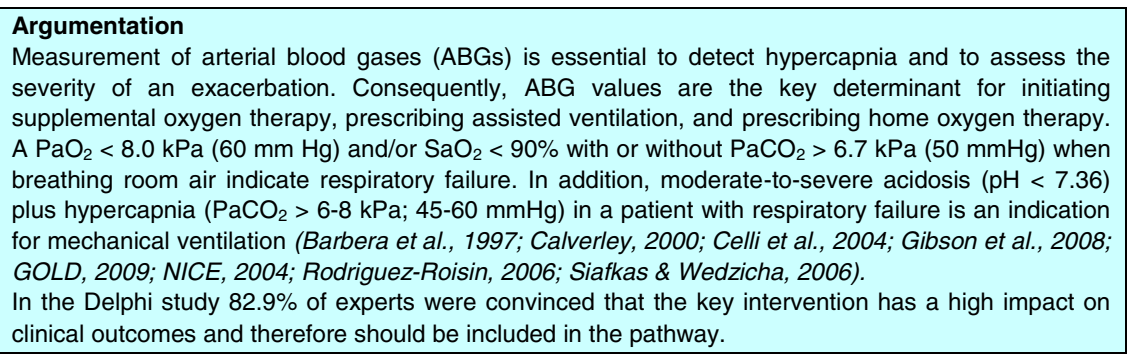

Description: (Celli et al., 2004; Gibson et al., 2008; GOLD, 2009; NICE, 2004; Rodriguez-Roisin, 2006; Siafkas \& Wedzicha, 2006)

Measurement of $\mathrm{PaO}_{2}, \mathrm{PaCO}_{2}, \mathrm{H}_{2} \mathrm{CO}_{3}^{-}, \mathrm{SaO}_{2}$, and $\mathrm{pH}$ by arterial puncture (a. radialis, brachialis, or femoralis) while breathing room air at admission. If measurement of $A B G$ while breathing room air is not feasible (severe cases), oxygen flow ( $/ / \mathrm{min}$ ) should be noted. Twenty to 30 minutes should pass before rechecking the gas tensions when the $\mathrm{FiO}_{2}$ has been changed.

References:

Barbera, J. A., Roca, J., Ferrer, A., Felez, M.A., Diaz, O., Roger, N., Rodriguez-Roisin, R. (1997). Mechanisms of worsening gas exchange during acute exacerbations of chronic obstructive pulmonary disease. European Respiratory Journal, 10, 1285-91.

Calverley, P.M. (2000). Oxygen-induced hypercapnia revisited. Lancet, 356:1538-1539.

Celli, B. R. \& Macnee, W. (2004). Standards for the diagnosis and treatment of patients with COPD: a summary of the ATS/ERS position paper. European Respiratory Journal, 23(6), 932-946.

Gibson G \& Macnee W. (2008). Chronic Obstructive pulmonary disease: Investigations and assessment of severity. In: Siafkas (Ed), European Respiratory Monograph: Management of exacerbation of chronic obstructive pulmonary disease (pp. 24-40). Sheffield: European Respiratory Society Ltd.

Global Initiative for Chronic Obstructive Lung Disease (GOLD) (2009). Global strategy for the diagnosis, management, and prevention of chronic obstructive pulmonary disease. Last accessed: January 27, 2010. http://www.goldcopd.com/Guidelineitem.asp? $|1=2 \&| 2=1 \&$ intld=2003

National Institute for Clinical Excellence (NICE) (2004). Chronic obstructive pulmonary disease: national clinical guideline for management of chronic obstructive pulmonary disease in adults in primary and secondary care. Thorax, 59 (Suppl. 1), 1-53.

Rodriguez-Roisin, R. (2006). COPD exacerbations: management. Thorax 61, 535-544.

Siafkas N. M. \& Wedzicha J. A. (2006). Management of exacerbation of COPD. In: Siafkas (Ed), European Respiratory Monograph: Management of exacerbation of chronic obstructive pulmonary disease (pp. 387-400). Sheffield: European Respiratory Society Ltd.

Figure 3 Example of detailed description of a key intervention: arterial blood gas measurement.

information on the description and the rationale, selected publications and their reference list were explored. Second, information from the additional literature search, performed to establish level of evidence (step 4), was included.

\section{Step 7: Translation into a set of process and outcome indicators}

Besides the set of key interventions, a set of process and outcome indicators needed to be developed to verify compliance to key interventions and to follow up the impact on outcomes. First, to select the final set of indicators, the expert panel convened for a consensus meeting. The selection process was based on the (updated) literature search (step 2), the Delphi survey (step 3), and the developed set of 38 evidence-based key interventions (step 5) [60]. As a result, a set of 24 process and 15 outcome indicators was developed, which are displayed in Additional file 2. The 24 process indicators include measurements on performance of diagnostic, pharmacological and non-pharmacological interventions. The 15 outcome indicators include measurements on readmission, mortality, length of stay (LOS), understanding of inhaler therapy, compliance with home oxygen therapy, performance of physical exercise, smoking status, anxiety and depression, health-related quality of life, management at home, functional status, self-reported health condition, medical consumption and an economic evaluation. On the basis of their expertise, the panel also selected a set of 15 baseline variables, including medical, socioeconomic, demographic and COPD-specific data.

Subsequently, the selected indicators and baseline variables were operationalized into objective measurements [65]. Based on the guidance of the Agency for Health 
Care Research and Quality (www.qualitymeasures.ahrq. gov) and the Joint Commission (www.jointcommission. org), each indicator and baseline variable was defined in an indicator protocol by the main researcher (CL). This process included defining of description, rationale or relation to quality, type of indicator (process, outcome, baseline), nominator and denominator, data collection method, data elements, data reporting (that is, proportion, relative proportion), criteria to meet expected outcomes, and references. An example of an indicator description is detailed in Additional file 3. Subsequently, the indicator protocol was mailed to the entire expert panel with a request to appraise each indicator description thoroughly for accuracy and feasibility. A meeting with the entire expert panel was convened to discuss the feedback and finalize the indicator protocol.

\section{Step 8: Piloting by multidisciplinary teams}

The set of 38 key interventions, and the set of 24 process and 15 outcome indicators, were piloted by nine Belgian experimental COPD teams in the context of the EQCP study [9]. The multidisciplinary teams included pulmonologists, nurses, physiotherapists, dieticians, social workers and occupational therapists. The piloting occurred in four phases. First, feasibility of data collection was evaluated during a clinical audit before pathway implementation. For this phase, 105 patients from 9 Belgium hospitals were included [9]. Mean age was 67 years (SD: 10.0 ), and $68.6 \%$ of the patients were male. Approximately half of the patients had severe COPD, $21 \%$ had moderate COPD and another $21.9 \%$ had very severe COPD. Overall, after data analyses we determined that data collection is feasible, and only minor adaptations with regard to the patient record analysis were included.

Second, during a workshop in which team members of all nine multidisciplinary COPD teams attended, the process flow diagram, including the 38 key interventions, was presented. Subsequently, all key interventions were extensively discussed. Third, the detailed set of key interventions was provided to the study coordinator of each hospital. We requested all members of the multidisciplinary COPD team to extensively review the key intervention set and subsequently to provide feedback within two weeks. As a result, the feedback given during the workshop and provided after extensive appraisal by all teams showed that teams were very enthusiastic about the process flow diagram and underlying key interventions. Moreover, they agreed by consensus that the set of key interventions was valid and applicable for use in their practice.

However, the teams provided four main remarks regarding: (i) usefulness of spirometry during exacerbation because results may be inaccurate due to the compromised condition; (ii) feasibility of referral to pulmonary rehabilitation with regard to condition of the patient and availability of a rehabilitation center; (iii) type of inhaler medications and device (nebulizer vs inhaler); and (iv) finally content, workload and feasibility of patient education. First, with regard to spirometry, no hard evidence about accuracy and, thus, usefulness of spirometric tests during exacerbation is available and, thus, no specific guidance on whether or not to perform spirometric tests could be provided to the teams. This issue was specifically emphasized in the detailed set of key interventions. Concerning pulmonary rehabilitation, all teams were convinced about the importance of referring patients to rehabilitation, and consequently, during the workshop some alternatives with regard to availability of a rehabilitation center were discussed. Finally, with regard to inhaler therapy and patient education, a teaching workshop was organized and education tools for COPD teams and ready-to-use patient leaflets were provided.

Finally, the nine multidisciplinary COPD teams implemented the set of key interventions as an active component of their care pathway for in-hospital management of COPD exacerbation in the context of the EQCP study [9]. Six months after the start of development and implementation of the care pathway, the nine teams had the opportunity to report experiences, barriers and successful actions during a workshop. One major difficulty in implementing the educational package into the daily work routine was reported. Overall, the teams confirmed validity and clinical applicability of the set of 38 key interventions.

\section{Discussion}

A set of 38 evidence-based key interventions for inhospital management of COPD exacerbation was developed (see Additional file 1) and, subsequently, piloted and validated by multidisciplinary COPD teams from nine different hospitals. This overall approval indicates that the applied strategy is appropriate for the development and standardization of the clinical content of an evidencebased care pathway. Second, a set of 24 process and 15 outcome indicators was also developed (see Additional file 2). The pilot study showed that the measurements on the indicators were feasible for the multidisciplinary teams and the patients; only some minor adaptations were required. Subsequently, based on our experience and what we have learned from the COPD case, we designed a generalized eight-step method (Figure 1), with the aim to guide and inspire teams caring for other patient groups in designing the clinical content of their future evidencebased care pathways.

It is important to note that designing the care pathway content according to the eight-step strategy is a timeconsuming process, especially with regard to the Delphi survey (step 3) and pilot testing (step 8). However, 
results of the Delphi survey and piloting are essential to ensure that the key intervention set is widely, clinically applicable. This is especially important when conducting a cRCT, in which the 'same' care pathway intervention needs to be implemented by different teams at different sites and possibly in different countries [9]. Teams developing care pathways should carefully plan an implementation strategy and budget enough time in their project plan for proper development of the clinical content of their care pathway.

A surprising finding is that, based on review of the literature (Step 2), the Delphi study, and face-to-face expert opinion, advanced care planning was not included in the set of 38 key interventions. On one hand, this can be explained due to the focus on management of acute COPD exacerbation. On the other hand, it is essential that advanced care planning and end of life discussions are initiated in advance of a life threatening situation, which can arise after COPD exacerbation [66]. Therefore, we acknowledge that an additional key-intervention with detailed reference to and description of advance life care planning should be included in this key intervention set.

An important limitation in the current strategy is the lack of patient involvement [67]. Patients can bring a different perspective to the quality improvement process, as they are likely to prioritize different aspects of care compared to clinicians, including interpersonal and amenity aspects; for example, communication with healthcare staff and quality of the food, rather than the technical and clinical aspects [68]. We believe that patients, for instance, by contacting patient societies, should have been involved in three phases of the eight-step method: (i) step 4: Final selection of the clinical activities; (ii) step 7: Translation into a set of indicators; and (ii) step 8: Piloting of the final set of key interventions. Including patients in these phases could have provided extra activities and outcomes, important from the patient perspective. After implementation of the key interventions, it will be interesting to gather information on patient preferences and opinions by performing open interviews with the patient and relatives, or by performing walk-throughs together with the patient [69]. Also, when applying the evidence-based care intervention in daily practice, clinicians should ensure that each of their individual patients is involved in decision making [67]. In this context, it is also recommended to develop a patient version that includes a brief and understandable summary of the set of key interventions.

We believe that developing the clinical care pathway content by using this newly developed and validated eight-step method will facilitate adequate integration of evidence-based knowledge into daily practice. Since the beginning of the 1990s, evidence-based clinical practice guidelines for almost all domains of medicine have been available worldwide, accessible more recently via the
Internet $[4,70,71]$. However, we see high variability in the integration of knowledge from evidence-based guidelines into daily practice $[4,72]$. Common barriers for integration of evidence-based knowledge are disagreement with the evidence; lack of outcome expectancy; lack of time; and available evidence, such as guidelines being unnecessarily complex, and thus not so directly applicable for clinical practice $[4,72,73]$. This eight-step methodology can facilitate translation of evidence-based knowledge into clinically applicable key interventions, which can overcome barriers and assist clinicians both in selecting the best treatment options and in delivering safe and effective care [4]. However, besides providing a set of detailed evidence-based key interventions, consideration of factors like culture (safety, commitment to do better in practice, peer norms); teamwork; skills management; communication; leadership alignment; and support will be critical to successfully integrate evidence into practice and improve the care process [74]. In this context, care pathways can be very effective tools, as they bring all these pieces together $[8,25,75]$.

Finally, we want to emphasize the potential role of professional medical associations in clinical content development for evidence-based care pathways. Many national and international societies have extensive clinical and research experience in the patient population of their clinical field, comprise a global network of experts in the field, have funding available and, last but not least, have comprehensive understanding and experience in synthesizing evidence-based knowledge and making this knowledge usable for daily clinical practice. Therefore, we believe that professional societies could play a major role in developing the clinical content of future evidence-based care pathways, especially in terms of clinical support, expert networking and input of resources.

\section{Conclusion}

The set of 38 key interventions and the set of process and outcome indicators were found to be appropriate for the development and standardization of the clinical content of the COPD care pathway in the context of a CRCT on pathway effectiveness. The developed eightstep method may facilitate multidisciplinary teams caring for other patient populations in designing the clinical content of their future care pathways.

\section{Additional files}

Additional file 1: Process flow diagram for in-hospital management
of COPD exacerbation. This Additional file displays a process flow chart
including 38 key interventions that should be performed for every
patient entering the hospital with COPD exacerbation. The key
interventions are classified under three core processes: Diagnostic,
Pharmacological and Non-pharmacological management.
of COPD exacerbation. This Additional file displays a process flow chart including 38 key interventions that should be performed for every interventions are Pharmacological and Non-pharmacological management. 
Additional file 2: Set of Process and outcome indicators for in-hospital management of COPD exacerbation. This Additional file displays a set of validated process and outcome indicators for audit of care for in-hospital management of COPD exacerbation.

\section{Additional file 3: Example of description of an indicator. This} Additional file displays the detailed description of an indicator according to the guidance of the Agency for Health Care Research and Quality (www.qualitymeasures.ahrq.gov) and the Joint Commission (www. jointcommission.org).

\section{Abbreviations}

ABGs: Arterial blood gases; ACCP: American College of Chest Physicians; ATS: American Thoracic Society; BMI: Body mass index; BTS: British Thoracic Society; COl: Cost of illness; COPD: Chronic obstructive pulmonary disease; CRCT: Cluster randomized controlled trial; DALY: Disability adjusted life years; E-P-A: European Pathway Association; EQCP: European Quality of Care Pathways; ERS: European Respiratory Society; FEV 1 : Forced expiratory volume in one second; FVC: Forced vital capacity; GOLD: Global Strategy for Diagnosis Management, and Prevention of COPD; HICPAC: Healthcare Infection Control Practices Advisory Committee; HRQL: Health-related quality of life; LOS: Length of stay; LTOT: Long-term oxygen therapy; NICE: National Institute for Health and Clinical Excellence; QALY: Quality-adjusted life expectancy measure; SIGN: Scottish Intercollegiate Guidelines Network: WHO: World Health Organization.

\section{Competing interests}

The authors declare that they have no competing interests.

\section{Authors' contributions}

$C L K V, W S, S D$ and MP contributed to the draft and the final version of the paper. MD supervised and was closely involved in the development of the clinical content of the care pathway intervention. MP, KV and WS have the scientific lead of the EQCP study. KV is international coordinator of the EQCP study. All authors have read and approved the final manuscript.

\section{Acknowledgements}

We acknowledge the Clinical Research Fund of UZ Leuven, Belgium for supporting this research. We also acknowledge Pfizer Belgium, Pfizer Italy, Pfizer Ireland and Pfizer Portugal who supported this research by providing an unrestricted educational grant. The autonomy of E-P-A and all involved academic institutions with regard to scientific independence and intellectual property on methodology is guaranteed. We further thank the Map of Medicine ${ }^{\circledR}$ for providing us the evidence based information, which helped us to develop the clinical pathway content. We acknowledge Rafaela Camacho Bejarano and Thierry Troosters for performing a pre-peer review on the manuscript.

\section{Author details}

${ }^{1}$ Respiratory Department, University Hospitals Leuven, Leuven, Belgium. ${ }^{2}$ Department of Public Health, KU Leuven University of Leuven, Leuven, Belgium. ${ }^{3}$ European Pathway Association, Kapucijnenvoer, Leuven, Belgium. ${ }^{4}$ Faculty of Medicine, KU Leuven University of Leuven, Leuven, Belgium. ${ }^{5}$ Department of Public Health, Department of Clinical and Experimental Medicine, Faculty of Medicine, Amedeo Avogadro University of Eastern Piedmont, Novara, Italy. ${ }^{6}$ Western Norway Research Network on Integrated Care, Helse Fonna, Haugesund, Norway.

Received: 20 May 2012 Accepted: 23 October 2012 Published: 29 November 2012

\section{References}

1. Institute of Medicine: Creating safety systems in health care organisations. In To Err is Human: Building a Safer Health System. Washington: National Academy Press; 2000:155-201.

2. Grol R, Grimshaw J: From best evidence to best practice: effective implementation of change in patients' care. Lancet 2003, 362:1225-1230.

3. Grol R, Wensing M: What drives change? Barriers to and incentives for achieving evidence-based practice. Med J Aust 2004, 180:S57-S60.
4. Institute of Medicine: Applying evidence to health care delivery. In Crossing the Quality Chasm. Washington, DC 20418: National Academy Press; 2001:145-163.

5. Lodewijckx C, Sermeus W, Vanhaecht K, Panella M, Deneckere S, Leigheb F, Decramer M: Inhospital management of COPD exacerbations: a systematic review of the literature with regard to adherence to international guidelines. J Eval Clin Pract 2009, 15:1101-1110.

6. Campbell $\mathrm{H}$, Hotchkiss $\mathrm{R}$, Bradshaw N, Porteous M: Integrated care pathways. BMJ 1998, 316:133-137.

7. Pearson SD, Goulart-Fisher D, Lee TH: Critical pathways as a strategy for improving care: problems and potential. Ann Intern Med 1995, 123:941-948.

8. Vanhaecht K, De Witte K, Sermeus W: The Care Process Organisation Triangle: a framework to better understand how clinical pathways work. Int J Care Pathw 2007, 11:1-8.

9. Vanhaecht K, Sermeus W, Peers J, Lodewijckx C, Deneckere S, Leigheb F, Decramer M, Panella M, for the EQCP Study Group: The impact of care pathways for exacerbation of chronic obstructive pulmonary disease: rationale and design of a cluster randomized controlled trial. Trials 2010, 11:111.

10. Medical Research Council: Developing and evaluating complex interventions: new guidance. http://www.mrc.ac.uk/Utilities/ Documentrecord/index.htm?d=MRC004871.

11. Sermeus W, De Bleser L, Depreitere R, Dewaele K, Vanhaecht K, Vlayen J: An introduction to clinical pathways. In KCE Reports Volume 18A: The Use of Clinical Pathways and Guidelines to Determine Physicians' Hospital Fees Prospectively: Easier Said Than Done. Edited by Devriese S, Lambert M, Eyssen M, Van de Sande S, Poelmans J, Van Brabandt H, Sermeus W, Vlayen J, Ramaekers D. Brussels: Belgian Healthcare Knowledge Centre (KCE); 2005:34-44. www.kenniscentrum.fgov.be/nl/publicaties.html.

12. Medical Research Council: Cluster Randomized Trials: Methodological and Ethical Considerations. http://www.mrc.ac.uk/Utilities/Documentrecord/ index.htm?d=MRC002406.

13. Oakley A, Strange V, Bonell C, Allen E, Stephenson J: Process evaluation in randomised controlled trials of complex interventions. BMJ 2006, 332:413-416.

14. Vanhaecht K, Ovretveit J, Elliott MJ, Sermeus W, Ellershaw J, Panella M: Have we drawn the wrong conclusions about the value of care pathways? Is a Cochrane review appropriate? Eval Health Prof 2012, 35:28-42.

15. Hawe P, Shiell A, Riley T: Complex interventions: how "out of control" can a randomised controlled trial be? BMJ 2004, 328:1561-1563.

16. Berry SA, Doll MC, McKinley KE, Casale AS, Bothe A Jr: ProvenCare: quality improvement model for designing highly reliable care in cardiac surgery. Qual Saf Health Care 2009, 18:360-368.

17. Schunemann HJ, Cook D, Guyatt G: Methodology for antithrombotic and thrombolytic therapy guideline development: American College of Chest Physicians Evidence-based Clinical Practice Guidelines. Chest 2008 133:113S-22S

18. Schunemann HJ, Hill SR, Kakad M, Vist GE, Bellamy R, Stockman L, Wisloff TF, Del Mar C, Hayden F, Uyeki TM, Farrar J, Yazdanpanah Y, Zucker H, Beigel J, Chotpitayasunondh T, Hien T, Ozbay B, Sugaya N, Oxman AD: Transparent development of the $\mathrm{WHO}$ rapid advice guidelines. PLOS Med 2007, 4:e119.

19. Umscheid CA, Agarwal RK, Brennan PJ: Updating the guideline development methodology of the Healthcare Infection Control Practices Advisory Committee (HICPAC). Am J Infect Control 2010, 38:264-273.

20. Goldmann D: Five puzzle pieces, ten cautionary notes. Int J Care Pathw 2010, 14:33-35.

21. Vanhaecht K, Deneckere S, Van Gerven E, Lodewijckx C, Janssens I, Van Zelm R, Boto P, Panella M, Biringer E, Sermeus W: The 7-phase method to design, implement and evaluate care pathways. Int J Pers Cent Med 2012 2:341-351

22. NHS Centre for Reviews and Dissemination (CRD): Systematic Reviews: CRD's guidance for undertaking reviews in health care. 2009, http://www.york.ac.uk/inst/crd/pdf/Systematic_Reviews.pdf.

23. Anzueto A, Sethi S, Martinez FJ: Exacerbations of chronic obstructive pulmonary disease. Proc Am Thorac Soc 2007, 4:554-564.

24. BMJ: Acute Exacerbation of Chronic Obstructive Pulmonary Disease. http://bestpractice.bmj.com/best-practice/monograph/8.html.

25. Cazzola M, MacNee W, Martinez FJ, Rabe KF, Franciosi LG, Barnes PJ, Brusasco V, Burge PS, Calverley PM, Celli BR, Jones PW, Mahler DA, Make B, 
Miravitlles M, Page CP, Palange P, Parr D, Pistolesi M, Rennard SI, Rutten-van Mölken MP, Stockley R, Sullivan SD, Wedzicha JA, Wouters EF, American Thoracic Society; European Respiratory Society Task Force on outcomes of COPD: Outcomes for COPD pharmacological trials: from lung function to biomarkers. Eur Respir J 2008, 31:416-469.

26. Evensen A: Management of COPD exacerbations. Am Fam Physician 2010 81:607-613.

27. Global Initiative for Chronic Obstructive Lung Disease: Global Strategy for the Diagnosis, Management, and Prevention Of Chronic Obstructive Pulmonary Disease. Revised 2011. http://www.goldcopd.org/uploads/users/ files/GOLD_Report_2011Dec30.pdf.

28. Glaab T, Vogelmeier C, Buhl R: Outcome measures in chronic obstructive pulmonary disease (COPD): strengths and limitations. Respir Res 2010, 11:79.

29. Hurst JR, Wedzicha JA: Management and prevention of chronic obstructive pulmonary disease exacerbations: a state of the art review. BMC Med 2009, 7:40

30. Kunisaki KM, Rice KL, Niewoehner DE: Management of acute exacerbations of chronic obstructive pulmonary disease in the elderly: an appraisal of published evidence. Drugs Aging 2007, 24:303-324.

31. Map of Medicine: Specialist Management of Acute Exacerbation. 2012, http://www.mapofmedicine.com.

32. National Institute for Health and Clinical Excellence (NICE): Chronic Obstructive Pulmonary Disease - Management of Chronic Obstructive Pulmonary Disease in Adults in Primary and Secondary Care. 2010, http://guidance.nice.org.uk/CG101.

33. Osthoff M, Leuppi JD: Management of chronic obstructive pulmonary disease patients after hospitalization for acute exacerbation. Respiration 2010, 79:255-261.

34. Rabbat A, Guetta A, Lorut C, Lefebvre A, Roche N, Huchon G: [Management of acute exacerbations of COPD]. Rev Mal Respir 2010, 27:939-953.

35. Rodriguez-Roisin R: COPD exacerbations: management. Thorax 2006 , 61:535-544

36. Scullion J: Patient-focused outcomes in chronic obstructive pulmonary disease. Nurs Stand 2008, 22:50-56.

37. Siafkas N, Wedzicha J: In Management of Chronic Obstructive Pulmonan Disease. Edited by Siafkas N. Sheffield: European Respiratory Society, Ltd; 2006:387-400

38. Vogelmeier $C$, Buhl $R$, Criee $C P$, Gillissen $A$, Kardos $P$, Kohler D, Magnussen H, Morr H, Nowak D, Pfeiffer-Kascha D, Petro W, Rabe K, Schultz K, Sitter H, Teschler $H$, Welte T, Ettengel R, Worth H: Guidelines for the diagnosis and therapy of COPD issued by Deutsche Atemwegsliga and Deutsche Gesellschaft fur Pneumologie und Beatmungsmedizin. Pneumologie 2007, 61:e1-40.

39. Bahadori K, FitzGerald JM: Risk factors of hospitalization and readmission of patients with COPD exacerbation-systematic review. Int J Chron Obstruct Pulmon Dis 2007, 2:241-251.

40. Chenna PR, Mannino DM: Outcomes of severe COPD exacerbations requiring hospitalization. Semin Respir Crit Care Med 2010, 31:286-294

41. Dal Negro R: Optimizing economic outcomes in the management of COPD. Int $J$ Chron Obstruct Pulmon Dis 2008, 3:1-10.

42. Decramer M, Celli B, Kesten S, Lystig T, Mehra S, Tashkin DP: Effect of tiotropium on outcomes in patients with moderate chronic obstructive pulmonary disease (UPLIFT): a prespecified subgroup analysis of a randomised controlled trial. Lancet 2009, 374:1171-1178.

43. Doll H, Miravitlles M: Health-related QOL in acute exacerbations of chronic bronchitis and chronic obstructive pulmonary disease: a review of the literature. Pharmacoeconomics 2005, 23:345-363.

44. Effing T, Monninkhof EM, Van der Valk PD, Van der Palen J, Van Herwaarden $\mathrm{CL}$, Partidge MR, Walters EH, Zielhuis GA: Self-management education for patients with chronic obstructive pulmonary disease. Cochrane Database Syst Rev 2007, 4:CD002990.

45. Eisner MD, Blanc PD, Yelin EH, Katz PP, Sanchez G, Iribarren C, Omachi TA: Influence of anxiety on health outcomes in COPD. Thorax 2010, 65:229-234.

46. Gartlehner G, Hansen RA, Carson SS, Lohr KN: Efficacy and safety of inhaled corticosteroids in patients with COPD: a systematic review and meta-analysis of health outcomes. Ann Fam Med 2006, 4:253-262.
47. Hartman JE, Boezen HM, de Greef MH, Bossenbroek L, Ten Hacken NH: Consequences of physical inactivity in chronic obstructive pulmonary disease. Expert Rev Respir Med 2010, 4:735-745

48. Lodewijckx C, Sermeus W, Vanhaecht K, Panella M, Deneckere S, Leigheb F Decramer M: Impact of care pathways for in-hospital management of COPD exacerbations: a systematic review. Int I Nurs Stud 2011, 48:1445-1456.

49. Poole PJ, Chacko E, Wood-Baker RW, Cates CJ: Influenza vaccine for patients with chronic obstructive pulmonary disease. Cochrane Database Syst Rev 2006, 1:CD002733.

50. Roche N, Rabbat A, Zureik M, Huchon G: Chronic obstructive pulmonary disease exacerbations in emergency departments: predictors of outcome. Curr Opin Pulm Med 2010, 16:112-117.

51. Rotter T, Kinsman L, James E, Machotta A, Gothe H, Willis J, Snow P, Kugler J: Clinical pathways: effects on professional practice, patient outcomes, length of stay and hospital costs. Cochrane Database Syst Rev 2010, 3:CD006632.

52. Seemungal TA, Hurst JR, Wedzicha JA: Exacerbation rate, health status and mortality in COPD-a review of potential interventions. Int I Chron Obstruct Pulmon Dis 2009, 4:203-223.

53. Steer J, Gibson GJ, Bourke SC: Predicting outcomes following hospitalization for acute exacerbations of COPD. QJM 2010, 103:817-829.

54. Stockley RA, Whitehead PJ, Williams MK: Improved outcomes in patients with chronic obstructive pulmonary disease treated with salmeterol compared with placebo/usual therapy: results of a meta-analysis. Respir Res 2006, 7:147.

55. Van Wetering CR, Hoogendoorn M, Mol SJ, Rutten-van Molken MP, Schols AM: Short- and long-term efficacy of a community-based COPD management programme in less advanced COPD: a randomised controlled trial. Thorax 2010, 65:7-13.

56. Yohannes AM, Willgoss TG, Vestbo J: Tiotropium for treatment of sTable COPD: a meta-analysis of clinically relevant outcomes. Respir Care 2011, $56: 477-487$

57. Campbell SM, Braspenning J, Hutchinson A, Marshall MN: Research methods used in developing and applying quality indicators in primary care. BMJ 2003, 326:816-819.

58. Hasson F, Keeney S, McKenna H: Research guidelines for the Delphi survey technique. J Adv Nurs 2000, 32:1008-1015.

59. Keeney S, Hasson F, McKenna H: Consulting the oracle: ten lessons from using the Delphi technique in nursing research. J Adv Nurs 2006, 53:205-212.

60. Lodewijckx C, Sermeus W, Panella M, Deneckere S, Leigheb F, Troosters T, Boto PAF, Mendez RV, Decramer M, Vanhaecht K: Quality indicators for inhospital management of exacerbation of chronic obstructive pulmonary disease: results of an international Delphi study. J Adv Nurs 2012, Epub ahead of print.

61. Siafkas N: Management of Chronic Obstructive Pulmonary Disease. Sheffield: European Respiratory Society, Ltd; 2006.

62. Atkins $D$, Best $D$, Briss PA, Eccles M, Famc-Ytter Y, Flottorp $S$, Guyatt $G H$, Harbour RT, Haugh MC, Henry D, Hill S, Jaeschke R, Leng G, Liberati A, Magrini N, Mason J, Middleton P, Mrukowicz J, O'Connell D, Oxman AD, Phillips B, Schunemann HJ, Edejer T, Varonen H, Vist GE, Williams JW Jr, Zaza S: Grading quality of evidence and strength of recommendations. BMJ 2004, 328:1490.

63. Scottish Intercollegiate Guidelines Network (SIGN): A Guideline Developer's Handbook: Annex B. http://www.sign.ac.uk/guidelines/fulltext/50/annexb. html.

64. Atkins D, Eccles M, Flottorp S, Guyatt GH, Harbour RT, Hill S, Jaeschke R, Liberati A, Magrini N, Mason J, O'Connell D, Oxman AD, Phillips B, Schunemann H, Edejer TT, Vist GE, Williams JW Jr: Systems for grading the quality of evidence and the strength of recommendations I: critical appraisal of existing approaches The GRADE Working Group. BMC Health Serv Res 2004, 4:38.

65. Mainz J: Defining and classifying clinical indicators for quality improvement. Int J Qual Health Care 2003, 15:523-530.

66. Klimanthianaki M, Mitrouska I, Georgopoulos D: Management of end-stage chronic obstructive pulmonary disease. In Management of Chronic Obstructive Pulmonary Disease. Edited by Siafkas N. Sheffield: European Respiratory Journals Ltd; 2006:430-450. 
67. Institute of Medicine: Improving the 21st-century health care system. In Crossing the Quality Chasm. Washington, DC 20418: National Academy Press; 2001:39-60.

68. Jaques H: Putting patients at the heart of quality. BMJ 2012, 344:e3164

69. Vanhaecht K, Panella M, Van Zelm R, Sermeus W: Is there a future for care pathways? Five pieces to the puzzle. Intl J Care Pathw 2009, 13:82-86.

70. Fervers B, Carretier J, Bataillard A: Clinical practice guidelines. J Visc Surg 2010, 147:e341-e349.

71. Pierson DJ: Clinical practice guidelines for chronic obstructive pulmonary disease: a review and comparison of current resources. Respir Care 2006, 51:277-288.

72. Cabana MD, Rand CS, Powe NR, Wu AW, Wilson MH, Abboud PA, Rubin HR: Why don't physicians follow clinical practice guidelines? A framework for improvement. JAMA 1999, 282:1458-1465.

73. Pierson DJ: Translating evidence into practice. Respir Care 2009, 54:1386-1401.

74. Dixon-Woods M, Bosk CL, Aveling EL, Goeschel CA, Pronovost PJ: Explaining Michigan: developing an ex post theory of a quality improvement program. Milbank Q 2011, 89:167-205.

75. Panella M, Brambilla R, Marchisio S, Di Stanislao F: Reducing stroke inhospital mortality: organized care is a complex intervention. Stroke 2008, 39:e186.

doi:10.1186/1745-6215-13-229

Cite this article as: Lodewijckx et al.: Eight-step method to build the clinical content of an evidence-based care pathway: the case for COPD exacerbation. Trials 2012 13:229.

\section{Submit your next manuscript to BioMed Central and take full advantage of:}

- Convenient online submission

- Thorough peer review

- No space constraints or color figure charges

- Immediate publication on acceptance

- Inclusion in PubMed, CAS, Scopus and Google Scholar

- Research which is freely available for redistribution 